\title{
MENGENALKAN AKUAPONIK SEBAGAI ALTERNATIF PENGEMBANGAN KETAHANAN PANGAN DAN EKONOMI DI SMAN 1 TASIK PAYAWAN
}

\author{
Rinto Alexandro ${ }^{1 *}$, Roossea Septiyani ${ }^{2}$, Fauzan Danurcahya $\operatorname{Ramadan}^{3}$, Indah Aldama ${ }^{4}$, Aris \\ Saputra $^{5}$, Boby Candra Andrianova ${ }^{6}$, Elfranidia Violetta ${ }^{7}$, Elvisia ${ }^{8}$, Henny Anggraini', \\ Heti Murdayanti $^{10}$, Inun Sulastri ${ }^{11}$, Kiki Anggraini Khoirati ${ }^{12}$, Okta Vianti ${ }^{13}$, \\ Putriana E M Nainggolan ${ }^{14}$, Rika Trisnawati ${ }^{15}$, Warsidah Sepriasih ${ }^{16}$ \\ $1,2,3,4,5,6,7,7,9,10,11,12,13,14,15,16$ Universitas Palangka Raya \\ *Email : rinto.alexandro@fkip.upr.ac.id,
}

\begin{abstract}
ABSTRAK
Mata pencaharian masyarakat di Desa Petak Bahandang sering dijumpai pada pertambangan emas dan bertani, namun dikarenakan kondisi alam yang tidak mendukung seperti banjir, perlu adanya alternatif lain agar mampu memenuhi kebutuhan pangan dan ekonomi masyarakat, sehingga akuaponik merupakan alternatif yang sangat tepat. Akuaponik merupakan kombinasi sistem budidaya ikan (akuakultur) dan budidaya tanaman tanpa media tanah (hidroponik). Sistem akuaponik menerapkan sistem ekologi secara alami yang terdapat hubungan saling menguntungkan antara ikan dan tanaman. Hubungan ini berupa kotoran yang dihasilkan dari budidaya ikan akan disalurkan kepada tanaman karena mengandung nutrisi atau unsur hara yang diperlukan oleh tanaman. Tanaman akan menyerap nutrisi yang dihasilkan dari kotoran ikan, dimana tanaman juga memberikan oksigen yang diperlukan oleh ikan melalui air yang sudah tersaring. Tujuan dari sistem akuaponik ini sangat menguntungkan karena dapat memperkuat perekonomian serta mampu membentuk kemandirian pangan dan gizi keluarga. Upaya mengenalkan akuaponik ke masyarakat terutama pada siswa SMAN-1 Tasik Payawan, metode yang digunakan yaitu metode sederhana dengan melibatkan peserta KKN-T dan mempraktekkan secara langsung. Siswa di SMAN-1 Tasik Payawan menyambut dengan baik serta ikut berpartisipasi dalam pelaksanaan kegiatan sehingga program kelompok dapat berjalan dengan baik.
\end{abstract}

Kata kunci: Akuaponik, akuakultur, hidroponik

\section{INTRODUCE AQUAPHONIC ALTERNATIVE DEVELOPMENT FOOD AND ECONOMIC RESISTANCE IN SMAN-1 TASIK PAYAWAN}

\begin{abstract}
People's livelihoods in Petak Bahandang Village are often found in gold mining and farming, but due to unfavorable natural conditions such as floods, alternative alternatives are needed to be able to meet food and economic needs of the community, so aquaponics is a very appropriate alternative. Aquaponics is a combination of fish farming systems (aquaculture) and plant cultivation without soil media (hydroponics). The aquaponics system applies a natural ecological system that has a mutually beneficial relationship between fish and plants. This relationship is in the form of dirt produced from fish farming that will be distributed to plants because it contains nutrients or nutrients needed by plants. Plants will absorb the nutrients produced from fish waste, where they also provide the oxygen needed by fish through filtered water. The purpose of this aquaponic system is very beneficial because it can strengthen the economy and is able to establish food independence and family nutrition. Efforts to introduce aquaponics to the community, especially for students of SMAN-1 Tasik Payawan, the method used is a simple method involving KKN-T participants and practicing it directly. Students at SMAN-1 Tasik Payawan welcomed and participated in the implementation of activities so that the group program could run well.
\end{abstract}

Keywords: Aquaponics, aquaculture, hydroponics 
https://ejurnal.stimi-bjm.ac.id/index.php/BBJM/

\section{PENDAHULUAN}

Kabupaten Katingan merupakan kabupaten baru hasil pemekaran dari kabupaten Kotawaringin Timur, dengan ibu kotanya adalah Kasongan. Letak geografis kabupaten Katingan memanjang dari utara ke selatan mengikuti aliran sungai katingan yang bermuara di laut Jawa. Kecamatan-kecamatan yang ada di kabupaten Katingan yang wilayahnya masuk dalam kawasan sebangau yaitu sebanyak 4 kecamatan yang terdiri dari: Kecamatan Tasik Payawan, Kamipang, Mendawai dan Katingan Kuala. Jumlah desa keseluruhan dari empat kecamatan tersebut sebanyak 34 desa dengan jumlah penduduk kurang lebih 41.516 jiwa. Luas wilayah kecamatan Tasik Payawan $804 \mathrm{Km}^{2}$ dengan ibukota Petak Bahandang. Kecamatan Tasik Payawan terdiri dari 8 desa, yang meliputi: Desa Luwuk Kanan, Luwuk Kiri, Tewang Tampang, Tumbang Panggo, Handiwung, Petak Bahandang, Hiyang Bana, dan Talingke. Kecamatan Tasik Payawan merupakan kecamatan yang paling ujung bagian utara Kabupaten Katingan dari area usulan kawasan perlindungan sebangau. Sebagian besar mata pencaharian masyarakat masih bergantung pada sumber daya alam, seperti nelayan, usaha keramba ikan, pengumpul rotan (netes), kayu, bekerja pada sektor jasa, dan sektor informal lainnya. Mata pencaharian masyarakat Kecamatan Tasik Payawan tidak jauh berbeda dengan mata pencaharian masyarakat lainnya. Bidang pertanian yang berbentuk sawah atau ladang terdapat di desa Luwuk Kiri, Luwuk Kanan dan desa Tewang Tampang, sedangkan usaha keramba ikan paling banyak dijumpai di desa Tumbang Panggo.

Teknologi akuaponik yang dikenal sebagai alternatif sistem pertanian terpadu tanpa memandang kondisi iklim maupun kondisi lahan yang ada. Akuaponik merupakan kombinasi sistem budidaya ikan dan budidaya tanaman tanpa ketergantungan terhadap tanah sebagai media tanam tanaman. Akuaponik belum banyak dikenal di masyarakat, berbeda dengan hidroponik yang sebagian orang sudah mengenalnya. Hidroponik hanya dikhususkan untuk tanaman sayuran atau bunga-bungaan yang ditanam pada media non-tanah dan untuk pemenuhan nutrisi disuplai melalui pupuk cair atau zat-zat kimia sebagai nutrisinya. Akuaponik memperoleh nutrisi sayuran lebih ditekankan pada pemanfaatan sumber air dari budidaya ikan, karena pada air sisa kotoran dan pakan ikan dapat menjadi bahan nutrisi bagi sayuran sehingga dengan sistem ini dapat menghemat tempat, air bahkan biaya dan tentunya lebih sehat dengan menghasilkan produk organik. Budidaya dengan sistem akuaponik menjamin kadar oksigen air dan menekan racun ammonia yang dihasilkan dari kotoran ikan. Menggabungkan hidroponik dan budidaya ikan akan mendekati sistem yang alami antara budidaya tanaman atau ikan. Kedua sistem itu saling melengkapi satu sama lain dimana ikan menghasilkan ammonia yang merupakan nutrisi bagi tanaman. Tanaman berfungsi sebagai mineralisasi atau mengurangi amoniak yang dapat meracuni ikan. Kadar oksigen dipelihara dengan berlangsungnya daur ulang air melalui sistem yang ada. Manfaat sistem aquaponik ini dalam skala kecil dapat bermanfaat sebagai pemenuhan kebutuhan rumah tangga, namun dalam skala besar bisa bermanfaat sebagai pemenuhan kebutuhan komersial. Meskipun secara umum masyarakat di Desa Petak Bahandang sudah sangat akrab dengan cara bertani dan bercocok tanam akan tetapi menggabungkan penanaman sayuran dengan pemeliharaan ikan masih merupakan hal baru dan di Desa Petak Bahandang sering terjadi banjir hingga lahan untuk bercocok tanam kadang terendam dan tidak dapat digunakan sehingga kegiatan pengabdian kepada masyarakat untuk memperkenalkan cara bertani akuaponik ini masih sangat perlu untuk dilakukan dikarenakan sistem akuaponik dapat dilakukan dilahan yang terbatas sekalipun.

\section{Pengertian Akuaponik}

Akuaponik adalah pergabungan antara sistem budidaya akuakultur (budidaya ikan) dengan hidroponik (budidaya tanaman tanpa media tanah). Sistem akuaponik menerapkan sistem ekologi secara alami yang terdapat hubungan saling menguntungkan antara ikan dan tanaman. Hubungan ini berupa, kotoran yang dihasilkan dari budidaya ikan akan disalurkan kepada tanaman karena mengandung nutrisi atau unsur hara yang diperlukan oleh tanaman. Tanaman akan menyerap nutrisi yang dihasilkan dari kotoran ikan tadi, dimana tanaman juga memberikan oksigen yang diperlukan oleh ikan melalui air yang sudah tersaring oleh media tanam (Yudi Sastro, 2016: 20-21). Akuaponik terdiri dari dua bagian utama. Bagian ini yaitu akuakultur untuk pemeliharaan hewan air dan bagian hidroponik untuk menumbuhkan tanaman. Pada akuakultur, limbah yang menumpuk di dalam air dapat bersifat racun bagi ikan. Limbah ini 
berasal dari feses dan urine ikan dan juga berasal dari sisa pakan yang tidak habis dimakan oleh ikan. Pada tanaman, justru limbah yang bersifat racun bagi ikan malah sebaliknya. Limbah tersebut sangat kaya akan nutrisi yang dapat menjadi sumber hara dan sangat bermanfaat bagi pertumbuhan tanaman, tetapi tentunya melalui sebuah proses dahulu sebelum siap digunakan sebagai sumber nutrisi oleh tanaman (Yudi Sastro, 2016: 21-22). Proses ini dimulai dari ikan yang memperoleh makanan dari pakan ikan buatan dan plankton (baik itu zooplankton maupun phytoplankton) yang tumbuh dalam sistem akuakultur. Makanan ini nantinya diproses oleh tubuh ikan dan akan menghasilkan limbah organik berupa feses dan urine. Limbah organik yang dikeluarkan ikan berbentuk ammonia $\left(\mathrm{NH}_{4}^{+}\right)$. Jika ammonia dalam konsentrasi tinggi, maka ammonia ini dapat menjadi racun yang bisa menyebabkan kematian pada ikan, sehingga perlu adanya bantuan bakteri untuk mengurai senyawa beracun ini menjadi tidak beracun (Yudi Sastro, 2016:22-23). Limbah ikan atau ammonia akan dimanfaatkan atau diurai oleh bakteri pengurai yang biasanya hidup pada dinding kultur, media tanam, dan media filter sebagai makanannya. Bakteri aerob ini akan merubah ammonia menjadi nitrit $\left(\mathrm{NO}_{2}{ }^{+}\right)$. Setelah menjadi nitrit, maka terjadi peran oleh bakteri anaerob yang merubah senyawa nitrit menjadi nitrat $\left(\mathrm{NO}^{+}\right)$. Nitrat umunya disebut unsur hara makro akan dimanfaatkan oleh tanaman bagi pertumbuhannya. Tanaman akan menyumbangkan oksigen (O2) sehingga air memiliki kualitas yang lebih baik bagi kehidupan di sistem ini (Yudi Sastro, 2016:23-24).

Sistem akuaponik sebenarnya juga memerlukan komponen lainnya atau sub sistem agar dapat berjalan maksimal, seperti:

1. Tangki pemeliharaan ikan.

2. Tangki pemisah dan penangkap limbah padat (filter mekanis).

3. Tangki sebagai tempat tinggal bakteri aerob dan anaerob (filter biologis).

4. Hidroponik sebagai tempat tanam tumbuhan.

5. Tangki pengumpul air bersih sebelum dipompa kembali ke kolam. (Yudi Sastro, 2016:25)

Akuaponik yang memadukan sistem pertanian budidaya tanaman dan ikan, ini bertujuan agar mampu menjadi sumber pemenuhan gizi keluarga dan masyarakat baik dari segi hewani maupun nabati. Hasil panen dari sistem ini juga bertujuan untuk dapat memperkuat perekonomian masyarakat (Sulistyo dkk, 2016: 101).

\section{Keunggulan dan Kelemahan Akuaponik}

Akuaponik memiliki keunggulan tertentu yaitu mampu diterapkan diwilayah yang sempit tanpa merusak kondisi ekosistem, tidak memerlukan media tanam, tidak memerlukan pupuk tambahan, penyiraman, dapat menghemat air, produknya sehat organik, memiliki nilai estetika, dan bebas dari pestisida. Akuaponik ini memiliki potensial besar dan sangat prospektif untuk dikembangkan ditempat yang sumber airnya susah dicari apabila musim kemarau, didaerah kering, dan padang pasir sekalipun bisa diterapkan (Yudi Sastro, 2016:20).

Adapun kelemahan akuaponik, yaitu biaya yang digunakan untuk membangun sistem dan perangkat pada awalnya memang cukup besar dan tidak ekonomis namun hasil yang didapat mungkin akan dapat membayar modal tersebut di lain hari. Biaya yang dikeluarkan biasanya digunakan untuk membeli segala peralatan dan bahan yang dibutuhkan untuk membuat sistem akuaponik tersebut. Kedua, membutuhkan listrik dan perawatan yang lebih optimal. Jenis metode ini kurang cocok digunakan pada daerah yang sering mengalami pemadaman listrik terutama jika menggunakan sistem Hidroponik NFT. Semakin sering atau lama daya listrik yang dipakai biaya yang dikeluarkan juga akan semakin besar. Ketiga, instalasi yang dibangun bergantung pada energi atau kontrol dari manusia. $\mathrm{pH}$ dan kadar oksigen harus selalu dijaga dan aerator harus selalu menyala agar selalu tercukupi.

\section{METODE}

Metode yang digunakan adalah metode sederhana dengan melibatkan seluruh peserta pengabdian secara aktif melalui diskusi dan menerapkan langsung, serta mengemukakan pendapat secara bebas sesuai dengan bidang dan keahliannya. Pelaksanaan dilapangan hanya melibatkan beberapa perwakilan siswa SMAN-1 Tasik Payawan dikarenakan masa pandemi COVID-19 ini yang membatasi perkumpulan massa. 
BAKTI BANUA : Jurnal Pengabdian Kepada Masyarakat

Volume 1 No. 1 Mei 2020

https://ejurnal.stimi-bjm.ac.id/index.php/BBJM/

Tahapan prosedur pelaksanaan KKN-T Periode I Tahun 2020 yaitu sebagai berikut.

1. Pembekalan mahasiswa

2. Penetapan dosen pembimbing

3. Pembekalan dosen pembimbing

4. Pengusulan dan verifikasi judul/topik kegiatan kelompok

5. Pembuatan jadwal kerja kelompok

6. Pembimbingan kegiatan kelompok

7. Penyampaian laporan kemajuan

8. Penulisan laporan kelompok dan naskah publikasi

9. Paparan laporan kelompok

10. Pengumpulan nilai

11. Pengumpulan laporan kelompok dan naskah publikasi

12. Pengumuman nilai dan pembagian sertifikat

Pengumpulan data adalah aktivitas mencari data yang dibutuhkan dalam rangka mencapai tujuan penelitian. Menggunakan metode observasi, dokumentasi, dan wawancara.

\section{Alat dan Bahan}

Alat adalah sesuatu yang digunakan untuk membuat sesuatu dan berupa benda. Bahan adalah sesuatu yang diperlukan dan merupakan bagian dari sesuatu yang akan dibuat. Alat dan bahan yang kami gunakan untuk membuat akuaponik rumahan adalah sebagai berikut :

Tabel 1. Alat dan Bahan yang digunakan

\begin{tabular}{|c|c|c|c|c|}
\hline No & Alat dan Bahan & Jumlah & \multicolumn{2}{|c|}{ Harga } \\
\hline 1. & Ember 80L & 1 buah & $\mathrm{Rp}$ & 85.000 \\
\hline 2. & Bak & 1 buah & $\mathrm{Rp}$ & 20.000 \\
\hline 3. & Pompa celup akuarium & 1 buah & $\mathrm{Rp}$ & 90.000 \\
\hline 4. & Pipa $1 / 2$ inch & 1 buah & $\mathrm{Rp}$ & 25.000 \\
\hline 5. & Pipa $21 / 2$ inch & 1 buah & $\mathrm{Rp}$ & 80.000 \\
\hline 6. & Penyambung pipa L $1 / 2$ inch & 7 buah & $\mathrm{Rp}$ & 24.000 \\
\hline 7. & Penyambung pipa L $21 / 2$ inch & 3 buah & $\mathrm{Rp}$ & 37.500 \\
\hline 8. & Penyambung pipa $\mathrm{T} 1 / 2$ inch & 1 buah & $\mathrm{Rp}$ & 4.000 \\
\hline 9. & Penutup pipa $21 / 2$ inch & 1 buah & $\mathrm{Rp}$ & 5.000 \\
\hline 10. & Stop kran $1 / 2$ inch & 2 buah & $\mathrm{Rp}$ & 30.000 \\
\hline 11. & Tisu untuk media tanam & Seperlunya & $\mathrm{Rp}$ & 10.000 \\
\hline 12. & Bibit tanaman & 1 Bungkus & $\mathrm{Rp}$ & 20.000 \\
\hline 13. & Bibit ikan & 50 Ekor & $\mathrm{Rp}$ & 50.000 \\
\hline 14. & Gelas plastic & Seperlunya & $\mathrm{Rp}$ & 10.000 \\
\hline 15. & Media filter mekanis & Seperlunya & $\mathrm{Rp}$ & 20.000 \\
\hline 16. & $\begin{array}{l}\text { Media filter biologis (bisa potongan } \\
\text { sedotan, tutup botol, potongan } \\
\text { bekas pipa, pecahan batu dll) }\end{array}$ & Seperlunya & & - \\
\hline 17. & Kayu & 3 buah & $\mathrm{Rp}$ & 40.000 \\
\hline & Total Harga & & & 550.500 \\
\hline
\end{tabular}


BAKTI BANUA : Jurnal Pengabdian Kepada Masyarakat

Volume 1 No. 1 Mei 2020

https://ejurnal.stimi-bjm.ac.id/index.php/BBJM/

\section{HASIL DAN PEMBAHASAN}

Pada dasarnya setiap kelompok yang mengikuti Kuliah Kerja Nyata Tematik (KKN-T) Periode I Tahun 2020 memiliki rencana program kelompok yang harus dilaksanakan sesuai dengan Tema Program yang sudah ditentukan oleh Lembaga Penelitian dan Pengabdian Kepada Masyarakat. Adapun rencana program kelompok A24 sebagai berikut:

Tabel 2. Rencana Program KKN

\begin{tabular}{|c|c|c|c|c|c|}
\hline No & Program Kegiatan & Volume & Lokasi & Sasaran & Pelaksana \\
\hline & $\begin{array}{l}\text { Koordinasi/perkenalan } \\
\text { dengan Kepala Sekolah } \\
\text { SMAN-1 Tasik Payawan }\end{array}$ & 1 hari & $\begin{array}{l}\text { Petak Bahandang- } \\
\text { Kecamatan Tasik } \\
\text { Payawan }\end{array}$ & $\begin{array}{l}\text { Siswa/i } \\
\text { SMAN-1 } \\
\text { Tasik } \\
\text { Payawan }\end{array}$ & $\begin{array}{c}\text { Seluruh } \\
\text { Mahasiswa/i } \\
\text { Kelompok A24 } \\
\text { KKN-T } \\
\text { Periode I } \\
\text { Tahun 2020 }\end{array}$ \\
\hline & $\begin{array}{l}\text { Penyampaian mengenai } \\
\text { kegiatan yang akan } \\
\text { dilaksanakan kepada Kepala } \\
\text { Sekolah SMAN-1 Tasik } \\
\text { Payawan yang akan } \\
\text { dilaksanakan di SMAN-1 } \\
\text { Tasik Payawan }\end{array}$ & 1 hari & $\begin{array}{l}\text { Petak Bahandang- } \\
\text { Kecamatan } \\
\text { Tasik Payawan }\end{array}$ & $\begin{array}{l}\text { Siswa/i } \\
\text { SMAN-1 } \\
\text { Tasik } \\
\text { Payawan }\end{array}$ & $\begin{array}{c}\text { Seluruh } \\
\text { Mahasiswa/i } \\
\text { Kelompok } \\
\text { A24 KKN-T } \\
\text { Periode I Tahun } \\
2020\end{array}$ \\
\hline
\end{tabular}

$\begin{array}{ccc}\text { 3. Observasi Lokasi } 1 \text { hari } & \text { Petak Bahandang- } & \text { Aris Saputra, } \\ & \text { Kecamatan Tasik } & \text { Elvisia, Fauzan } \\ & \text { Payawan } & \text { DanurcahyaR } \\ & & \text { amadhan, Inun } \\ & & \text { Sulatri, Warsidah } \\ & & \text { Sepriasih }\end{array}$

\begin{tabular}{|c|c|c|c|c|}
\hline $\begin{array}{l}\text { 4. Koordinasi mengenai } \\
\text { perencanaan kerja dengan } \\
\text { pihak sekolah SMAN-1 } \\
\text { Tasik Payawan }\end{array}$ & 1 hari & $\begin{array}{l}\text { Petak Bahandang- } \\
\text { Kecamatan Tasik } \\
\text { Payawan }\end{array}$ & $\begin{array}{l}\text { Siswa/i } \\
\text { SMAN- } \\
\text { 1Tasik } \\
\text { Payawan }\end{array}$ & $\begin{array}{c}\text { Seluruh } \\
\text { Mahasiswa/i } \\
\text { Kelompok A24 } \\
\text { KKN-T } \\
\text { Periode I }\end{array}$ \\
\hline
\end{tabular}

Tahun 2020

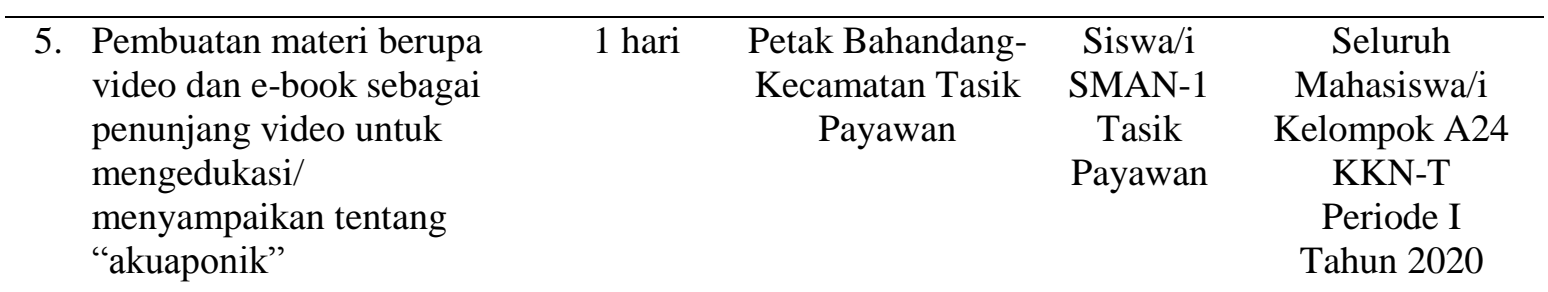


BAKTI BANUA : Jurnal Pengabdian Kepada Masyarakat

Volume 1 No. 1 Mei 2020

https://ejurnal.stimi-bjm.ac.id/index.php/BBJM/

Adapun pembagian tim dalam melaksanan program sebagai berikut:

Tabel 3. Pembagian Tim

\begin{tabular}{|c|c|c|}
\hline No & Program Kegiatan & Pembagian Tim \\
\hline 1. & $\begin{array}{l}\text { Koordinasi/perkenalan dengan } \\
\text { Kepala Sekolah SMAN-1 Tasik } \\
\text { Payawan }\end{array}$ & $\begin{array}{l}\text { Seluruh Mahasiswa/I Kelompok A24 KKN- } \\
\text { T Periode I Tahun } 2020\end{array}$ \\
\hline 2. & $\begin{array}{l}\text { Penyampaian mengenai kegiatan } \\
\text { yang akan dilaksanakan kepada } \\
\text { Kepala Sekolah SMAN-1 Tasik } \\
\text { Payawan yang akan dilaksanakan di } \\
\text { SMAN-1 Tasik Payawan }\end{array}$ & $\begin{array}{l}\text { Seluruh Mahasiswa/I Kelompok A24 } \\
\text { KKN- T Periode I Tahun } 2020\end{array}$ \\
\hline 3. & Observasi Lokasi & $\begin{array}{l}\text { Aris Saputra, Elvisia, Fauzan } \\
\text { Danurcahya } \\
\text { Ramadhan, Inun Sulatri, Warsidah } \\
\text { Sepriasih }\end{array}$ \\
\hline 4. & $\begin{array}{l}\text { Koordinasi mengenai perencanaan } \\
\text { kerja dengan pihak sekolah SMAN- } \\
1 \text { Tasik Payawan }\end{array}$ & $\begin{array}{l}\text { Seluruh Mahasiswa/I Kelompok A24 } \\
\text { KKN- T Periode I Tahun } 2020\end{array}$ \\
\hline 5. & $\begin{array}{l}\text { Pembuatan materi berupa video } \\
\text { untuk memberikan edukasi tentang } \\
\text { "akuaponik" }\end{array}$ & $\begin{array}{ll}\text { - } & \text { Aris Saputra } \\
\text { - } & \text { Elfranidia Violetta } \\
\text { - } & \text { Putriana E M Nainggolan } \\
\text { - } & \text { Inun Sulastri } \\
\text { - } & \text { Warsidah Sepriasih } \\
\text { - } & \text { Fauzan Danurcahya Ramadhan }\end{array}$ \\
\hline 6. & $\begin{array}{l}\text { Pembuatan e-book sebagai bahan } \\
\text { penunjang vidio dan berisi bahan } \\
\text { materi tentang "akuaponik" }\end{array}$ & $\begin{array}{ll}\text { - } & \text { Boby Candra Andrianova } \\
\text { - } & \text { Heti Murdayanti } \\
\text { - } & \text { Henny Anggraini } \\
\text { - } & \text { Indah Aldama } \\
\text { - } & \text { Kiki Anggraini Khoirati } \\
\text { - } & \text { Okta Vianita } \\
\text { - } & \text { Rika Trisnawati } \\
\text { - } & \text { Roossea Septiyani }\end{array}$ \\
\hline
\end{tabular}

Pelaksanaan kegiatan KKN merupakan bentuk realisasi dari rancangan agenda yang tercantum dalam program kerja. Idealnya dalam pelaksanaan program kerja tersebut semestinya sesuai dengan apa yang terjadwal pada program kerja. Namun, untuk KKN tahun ini terdapat kendala dan hambatan yang membuat realisasi dari program kerja yang diagendakan tidak sesuai dengan yang dijadwalkan. Jadi, yang seharusnya KKN dilaksanakan 1-2 bulan di tahun-tahun sebelumnya tapi untuk tahun ini KKN dilaksanakan dalam waktu satu bulan secara Online. Pelaksanaan kegiatan yang kami laksanakan cuma 1 hari ke Desa Petak Bahandang pada hari Rabu tanggal 24 Juni 2020. Adapun mengenai keterlaksanaan program dapat dilihat pada tabel dibawah ini: 
BAKTI BANUA : Jurnal Pengabdian Kepada Masyarakat

Volume 1 No. 1 Mei 2020

https://ejurnal.stimi-bjm.ac.id/index.php/BBJM/

Tabel 4. Keterlaksanaan Program

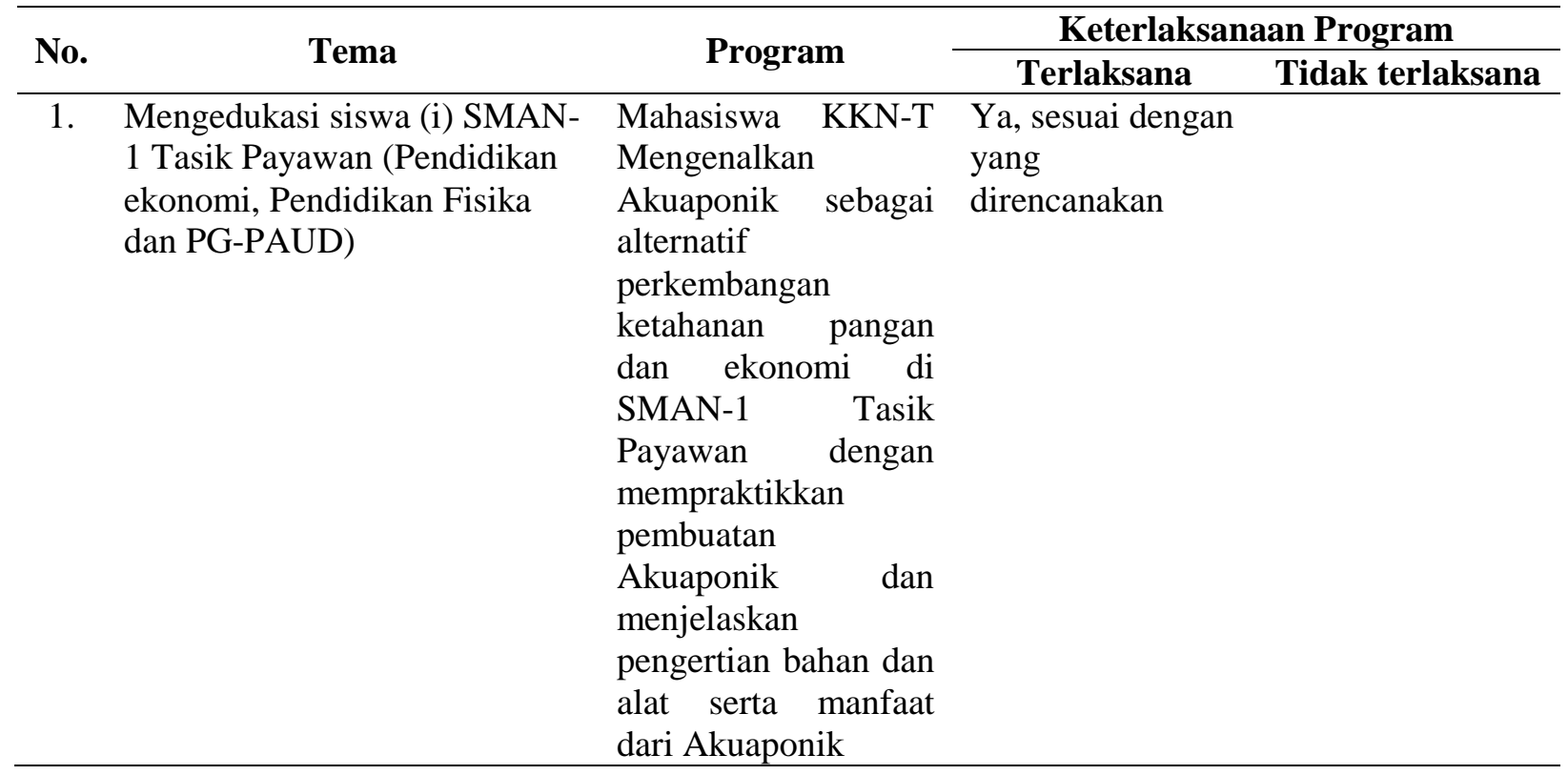

Adapun faktor pendukung dan penghambat yang ditemukan di Desa Petak Bahandang yaitu Faktor Pendukung, antara lain:

1. Jaringan internet

2. Listrik

3. PDAM

Faktor Penghambat, antara lain:

1. Lokasi yang terlalu jauh dari kota.

2. Ada beberapa jalan yang rusak akibat banjir

3. Kurangnya penggunaan android bagi siswa(i) di SMAN-1 Tasik Payawan

Upaya mengatasi hambatan yang ada pada saat pelaksaan kegiatan, kami menggunakan transportasi yang membantu dalam mempermudah perjalanan karena jauh dari kota dan dapat melewati jalanan yang rusak akibat banjir dan untuk kurangnya pengunaan android bagi siswa(i) di SMAN-1 Tasik Payawan, kami membagi kelompok dan menyebar video kepada ketua dari kelompok agar dalam kelompok semuanya dapat mempelajari materi yang kami berikan. Supaya pada saat praktik siswa(i) sudah cukup memiliki pengetahuan tentang akuaponik.

Faktor-faktor yang mendukung Keberhasilan program kegiatan KKN-T yang dilaksanakan di Petak Bahandang adalah disiplin, rajin, keikutsertaan, keterlibatan, kehadiran, keseriusan, dan pelaksanaan program kerja KKN-T di Desa Petak Bahandang berhasil dilaksanakan dengan baik. Meskipun terdapat sedikit kendala namun semua bisa diatasi dengan semangat dan kerjasama yang baik oleh anggota KKN-T dan dukungan masyarakat Desa Petak Bahandang. Setiap selesai melakukan kegiatan, mahasiswa mencatat laporan kegiatan di buku harian kegiatan Kuliah Kerja Nyata-Tematik untuk mengetahui capaian program dan laporan kepada panitia KKN-T. Selesai kegiatan KKN-T mahasiswa membuat laporan akhir kegiatan Kuliah Kerja Nyata-Tematik secara kelompok.

\section{KESIMPULAN}

Kuliah Kerja Nyata Tematik (KKN-T) merupakan tempat atau wadah dan ajang bagi mahasiswa untuk belajar hidup di masyarakat. Kegiatan KKN ini diharapkan agar mahasiswa dapat berperan dan berpartisipasi secara aktif dalam masyarakat, memberikan pengalaman baik fisik dan mental agar dapat menempa diri dan mengembangkan wawasan intelektual. 
Pelaksanaan kegiatan KKN-T berlangsung pada tanggal 28 Mei 2020 hingga 30 Juni 2020 dengan kegiatan yang berhubungan dengan pelaksanaan program dan pembuatan laporan hasil dari kegiatan. Program KKN-T 2020 dilaksanakan di Desa Petak Bahandang, Kecamatan Tasik Payawan, Kabupaten Katingan, Provinsi Kalimantan Tengah pada tanggal 24 Juni 2020. Terdapat 1 tema yang telah terlaksana yaitu Pertanian Terpadu Akuaponik sebagai Pengembangan Ketahanan Pangan dan Ekonomi. Berdasarkan dari kegiatan-kegiatan yang telah terlaksana dapat diambil kesimpulan, diantaranya sebagai berikut:

1. Mahasiswa KKN dapat mengidentifikasi kebutuhan masyarakat dari berbagai macam permasalahan serta dapat menggali potensi yang dimiliki oleh masyarakat sebagai bahan acuan untuk merencanakan dan melaksanakan program kerja.

2. Mahasiswa KKN dituntut untuk dapat hidup bermasyarakat dan memahami realita masyarakat dengan menggunakan pengetahuan, sikap dan keterampilan yang dimilikinya.

3. Program kerja KKN yang dilaksanakan sebagian besar dapat berjalan dengan baik, walaupun ada penyesuaian waktu dengan kondisi dan situasi lingkungan masyarakat.

4. Keberhasilan program-program KKN pada akhirnya diharapkan agar dapat memberikan manfaat yang saling menguntungkan antara masyarakat dan mahasiswa itu sendiri. Dampak positif bagi mahasiswa adalah meningkatkan kepedulian terhadap lingkungan sekitar dan memperluas cakrawala pemikiran, sedangkan bagi masyarakat adalah meningkatkan keinginan untuk maju, sikap mental positif, pola pikir kritis yang pada akhirnya mampu mengembangkan pembangunan diri dan lingkungan.

5. Desa Petak Bahandang Kecamatan Tasik Payawan Kabupaten Katingan merupakan desa yang kaya akan potensi pertambangan, masyarakat juga masih memegang teguh nilai adat budaya seperti gotong royong, peduli antar sesama dan membantu antar sesama dan dimana dapat dikatakan masyarakat Desa Tasik Payawan sadar akan Budaya Handep Hapakat.

6. Sebagai peserta Kuliah Kerja Nyata Tematik (KKN-T) Periode I Tahun 2020 khususnya Kelompok A-24 mengucapkan terima kasih yang sebesar-besarnya kepada Universitas Palangka Raya yang sudah menyelenggarakan KKN-T yang bertujuan untuk melaksanakan kegiatan yang mampu mendorong kemandirian dan kesejahteraan masyarakat secara berkelanjutan.

\section{DAFTAR PUSTAKA}

Aliayub, Adri. 2002. Laporan Survey Pendahuluan Sosial-Ekonomi Dan Monografi Desa Di Sekitar DAS Katingan Dan Sebangau Kalimantan Tengah. Palangka Raya: WWF Indonesia.

Anonim. 2020. Akuaponik Sistem Kelebihan Dan Kelemahan. http://urbanina.com/akuaponik/akuaponik-kelebihan-dan-kelemahan/ (Diakses pada tanggal 12 Juni 2020)

Iswandi, R.M, dkk. 2020. Pemanfaatan Lahan Pekarangan Untuk Pertanian dan Perikanan Dalam Menunjang Ketahanan Pangan Rumah Tangga Masyarakat di Kelurahan Bungkutoko Kecamatan Nambo Kota Kediri. Jurnal Pengabdian Masyarakat Ilmu Terapan. 2(1): hlm 1-6.

Sastro, Y. 2016. Teknologi Akuaponik Mendukung Pengembangan Urban Farming. Jakarta: BPTP Jakarta.

Sulistyo, M.A.B, dkk. 2016. Teknologi Akuaponik Untuk Memperkuat Ekonomi Warga RW 10 Kelurahan Bandungrejosari Kota Malang. Senaspro2016. hlm. 99-109. 